\title{
MANTLE DEVOLATILIZATION AND CONVECTION: IMPLICATIONS FOR THE THERMAL HISTORY OF THE EARTH
}

\author{
Michael J. Jackson and Henry N. Pollack
}

Department of Geological Sciences, The University of Michigan

\begin{abstract}
The depletion of volatiles from the earth's mantle over its history may have had significant effects on thermal convection, due to the effects of volatiles on silicate rheology. Experimental data suggest that the activation energy for solid-state creep in a volatile-free environment is as much as $25 \%$ greater than in a volatilerich environment, and thus devolatilization can lead to a substantial increase in viscosity. In a devolatilizing system, gradually increasing temperatures (relative to those in a system with volatile-independent rheology) may be required to maintain moderate viscosities and convection. We investigate this postulated effect by incorporating a time-dependent increase in activation temperature, simulating progressive mantle devolatilization, in a parameterized convection model. Volatiles significantly affect the earth's thermal evolution when the dependence of mantle rheology upon volatile content is sufficiently strong, the total volatile loss is sufficiently large, and devolatilization is relatively slow and continuous. For models with an increase of $20 \%$ in activation energy over earth history, the present-day ratio of heat production to heat loss (Urey ratio) approaches or exceeds 1.0 when volatile loss is relatively continuous. With rapid early volatile loss, the upper bound on the present-day Urey ratio is about 0.8 to 0.9 , comparable to the limit with volatile-independent rheology. Present uncertainties in these factors permit an earth that may be close to a steady thermal state or perhaps even warming up.
\end{abstract}

\section{Introduction}

The strong temperature dependence of silicate rheology is of critical importance in convective evolution of the mantle, a point emphasized by Tozer [1965; 1972 ] and presently agreed on by most researchers. Temperature-dependent viscosity tends to regulate both temperature and viscosity to values just sufficient to remove heat from the mantle via moderate convection. Another factor which has a strong influence on rheology, and which has been ignored to date in mantle convection models, is the volatile content. The presence of volatiles such as $\mathrm{H}_{2} \mathrm{O}$ and $\mathrm{CO}_{2}$ may significantly reduce creep strength and melting temperatures in silicates. Progressive devolatilization of the mantle may therefore be accompanied by an evolving rheology with increasing viscosity and less efficient heat transfer. We assess the possible effects of mantle devolatilization on terrestrial thermal evolution, by means of a parameterized convection model with volatile-dependent rheology.

\section{Copyright 1987 by the American Geophysical Union}

Paper number 7L7168.

0094-8276/87/007L-7168\$03.00

\section{Volatile-Dependent Mantle Rheology}

In numerical convection models, rheology is usually represented as an exponential function of temperature:

$$
\nu=\nu_{0} \exp \left(E_{A} / k T\right)
$$

where $\nu$ is the kinematic viscosity, $\nu_{0}$ is a constant, $E_{A}$ is the activation energy for solid state creep, $k$ is Boltzmann's constant and $T$ is the absolute temperature. Weertman and Weertman [1975] give as an alternate but equivalent expression:

$$
\nu=\nu_{0} \exp \left(g T_{m} / T\right)
$$

where $T_{m}$ is the melting temperature and $g$ a dimensionless constant, approximately 30 . An activation temperature $T_{A}\left(=E_{A} / k=g T_{m}\right)$ is another commonly defined and useful quantity [e.g., Schubert et al., 1980].

Laboratory deformation experiments on olivine have shown that small amounts of $\mathrm{H}_{2} \mathrm{O}$ lead to a reduction of creep strength, with an accompanying reduction of activation temperature by as much as $25 \%$ [Carter, 1976; Post, 1977; Chopra and Paterson, 1984]. The peridotite solidus temperature is also depressed by as much as $25 \%$ to $30 \%$ in the presence of $\mathrm{H}_{2} \mathrm{O}$ and/or $\mathrm{CO}_{2}$ [Green, 1973; Mysen and Boettcher, 1975; Eggler, 1978; Wyllie, 1979]. By eq. 2, these results indicate a change in activation temperature of comparable magnitude to that observed in the deformation experiments. Thus, although the deformation experiments have been the subject of various criticisms [Justice et al., 1982], the similarity of the observed effects of volatiles both on melting and on laboratory deformation strengthens the case for a volatile-dependent rheology in the mantle. Further, while the relevance of laboratory deformation experiments to mantle rheology is made somewhat uncertain by extrapolation over many orders of magnitude of strain rate [Paterson, 1987], the results of laboratory melting experiments are essentially free of such raterelated uncertainties. Thus volatiles are likely to have significant effects on mantle rheology and convection.

Quantitative data on the functional dependence of activation temperature on $\mathrm{H}_{2} \mathrm{O}$ content are not available for mantle rocks, but have been published for other silicates. Systematic variation of $T_{A}$ with $\mathrm{H}_{2} \mathrm{O}$ content was demonstrated by Kronenberg and Tullis [1984] for quartz aggregates and by Jaoul et al. [1984] for quartzite. These results are summarized in Table 1. Table 1 also shows, for comparison, values of activation temperature for peridotite inferred by us from the melting experiments described above $\left(T_{A}=g T_{m}, g=30\right)$. Because the solidus of peridotite containing $0.1 \% \mathrm{H}_{2} \mathrm{O}$ lies about half-way between the solidi of anhydrous and $\mathrm{H}_{2} \mathrm{O}$-saturated peridotite [Wyllie, 1979; Ringwood, 
Table 1. Activation Temperature and Water Content

\begin{tabular}{clccc}
\hline$\% \mathrm{H}_{2} \mathrm{O}$ & Rock Type & $T_{A}\left[10^{4} \mathrm{~K}\right]$ & $\frac{T_{A}}{T_{A, D}}$ & $\frac{\left(T_{A}-T_{A, W}\right)}{\left(T_{A, D}-T_{A, W}\right)}$ \\
\hline "dry" & peridotite & 7.20 & 1.00 & 1.00 \\
"dry" & quartz ag. & 3.61 & 1.00 & 1.00 \\
"dry" & quartzite & 2.21 & 1.00 & 1.00 \\
0.1 & peridotite & 6.40 & 0.89 & 0.50 \\
0.1 & quartz ag. & 2.43 & 0.67 & 0.42 \\
0.1 & quartzite & 2.06 & 0.93 & 0.67 \\
0.3 & quartzite & 1.76 & 0.80 & 0.00 \\
0.4 & quartz ag. & 1.56 & 0.43 & 0.00 \\
0.4 & quartzite & 1.81 & 0.82 & 0.10 \\
"wet" & peridotite & 5.60 & 0.78 & 0.00 \\
\hline
\end{tabular}

Subscripts "W" and "D" refer to wet and dry values, respectively. Quartzite data from Jaoul et al. (1984); quartz aggregate data from Kronenberg and Tullis (1984); peridotite values inferred from melting experiments (see text).

1975], $T_{A}(0.1 \%)$ lies half-way between the dry and saturated activation temperatures. By analogy with the quartzite data we assume that the full weakening effect occurs at $\mathrm{H}_{2} \mathrm{O}$ contents greater than about $0.3 \%$. Activation temperature appears to vary in a similar fashion for most silicates, although the magnitude of the change from wet to dry conditions may differ.

\section{Mantle Volatile Content and Devolatilization History}

Ringwood [1966, 1975] estimates that the amount of $\mathrm{H}_{2} \mathrm{O}$ in the mantle is at least three times that outgassed into the oceans, based on a comparison with a nitrogen loss model. Thus according to Ringwood the present-day mantle contains an average of $0.1 \% \mathrm{H}_{2} \mathrm{O}$. The $\mathrm{H}_{2} \mathrm{O}$ content therefore appears to lie in the range where it should significantly affect viscosities. This estimate is subject to at least a factor of two uncertainty, and probably considerable spatial variation. Larimer [1971] estimates that no more than $50 \%$ of the earth's total $\mathrm{H}_{2} \mathrm{O}$ is still in the mantle, based on the $\mathrm{H}_{2} \mathrm{O}$ content of upper-mantle derived basalts. Thus, the inferred ratios of initial to present-day mantle $\mathrm{H}_{2} \mathrm{O}$ content range from less than 1.3 to greater than 2 . The time-dependence of mantle degassing is also subject to considerable uncertainty. Sarda et al. [1985] propose an efficient early degassing model with $>90 \%$ loss of Ar and $\mathrm{Xe}$ from the mantle within the first few hundred $\mathrm{Ma}$, whereas Fisher [1985] has argued for a more continuous degassing history (see Staudacher and Sarda [1987] and Fisher [1987] for further discussion). The loss of these noble gases with time can be taken as upper limits for the loss of the more chemically active volatiles. We consider as plausible earth models those with degassing histories ranging from rapid early devolatilization to slower, nearly uniform loss rates over earth history, and initial/final $\mathrm{H}_{2} \mathrm{O}$ content ratios between 1 and 3 .

\section{Model}

\section{Parameterized Mantle Convection}

Parameterized convection models are based on the theoretical and empirical relation between the heat flux out of a convecting system and the temperature difference driving the convection, expressed in terms of the Nusselt $(N u)$ and Rayleigh $(R a)$ numbers:

$$
N u=\left(R a / R a_{c r \imath t}\right)^{\beta}
$$

The value of the constant $\beta$ is near $1 / 3$ [Richter et al., 1983; Schubert and Anderson, 1985]. An ordinary differential equation for $d T / d t$ can be derived from (3) and energy conservation. The change in the heat content of the mantle with time is determined by the difference between heat production and heat loss. A dimensionless quantity which is related to the efficiency of heat transfer in the mantle at a given time is the ratio of heat production to heat loss, or Urey ratio. A Urey ratio less than unity corresponds to a cooling earth. In this paper we utililize the model equations of Schubert et al. [1980], with the nominal parameter values given in Table 2 , and the time scale of radiogenic heating governed by a terrestrial K/U ratio [Jackson and Pollack, 1984].

\section{Time-Dependent Activation Temperature}

In order to include directly the effects of devolatilization in a parameterized model, it is necessary to specify both the dependence of viscosity upon mantle volatile content, and the volatile content as a function of time. Due to the large uncertainty in each of these functions, we have instead made activation temperature $T_{A}$ a direct function of $t$ :

$$
T_{A}(t)=T_{A 0}\left(1+\left(\Delta T_{A} / T_{A 0}\right)(t / 4.6)^{\tau}\right)
$$

with $0 \leq \tau \leq 1$ and $0 \leq t \leq 4.6$ Ga. $\Delta T_{A}$ is the total change in activation temperature over earth history, $T_{A 0}$ is the initial value, and $\tau$ describes the time dependence. By suitable choice of parameter values, we can use eq. 4 to encompass the range of possibilities in both the volatile-dependence of viscosity and the degassing history of the earth. The limiting case $\Delta T_{A}=0$ corresponds to the traditional volatile-independent rheology, in which activation temperature is constant. Non-zero values of $\Delta T_{A}$ correspond to a more strongly volatiledependent rheology and/or larger total volatile loss. The temporal behavior is controlled by the time constant $\tau$. For $0<\tau<<1$, the activation temperature $T_{A}(t)$ increases rapidly early in earth history, and then gradually approaches $T_{A p}$, appropriate for efficient early degassing models. Continuous degassing models can be

Table 2. Parameter Nominal Values

\begin{tabular}{lll}
\hline & Definition & Value \\
\hline$g$ & gravitational acceleration & $9.8 \mathrm{~m} \mathrm{~s}^{-2}$ \\
$\alpha$ & thermal expansivity & $3 \times 10^{-5} \mathrm{~K}^{-1}$ \\
$\kappa$ & thermal diffusivity & $10^{-6} \mathrm{~m}^{2} \mathrm{~s}^{-1}$ \\
$D$ & depth of convecting layer & $2.8 \times 10^{6} \mathrm{~m}$ \\
$\nu_{0}$ & minimum viscosity & $2.21 \times 10^{7} \mathrm{~m}^{2} \mathrm{~s}^{-1}$ \\
$k$ & thermal conductivity & $4.2 \mathrm{~W} \mathrm{~m} \mathrm{~K}^{-1}$ \\
$\beta$ & Nusselt-Rayleigh exponent & 0.3 \\
$\rho c$ & volumetric specific heat & $4.2 \times 10^{6} \mathrm{~J} \mathrm{~m}^{-3}$ \\
$R_{c}$ & core radius & $3471 \mathrm{~km}$ \\
$R_{m}$ & mantle outer radius & $6271 \mathrm{~km}$ \\
$T_{s}$ & surface temperature & $273 \mathrm{~K}$ \\
\hline
\end{tabular}



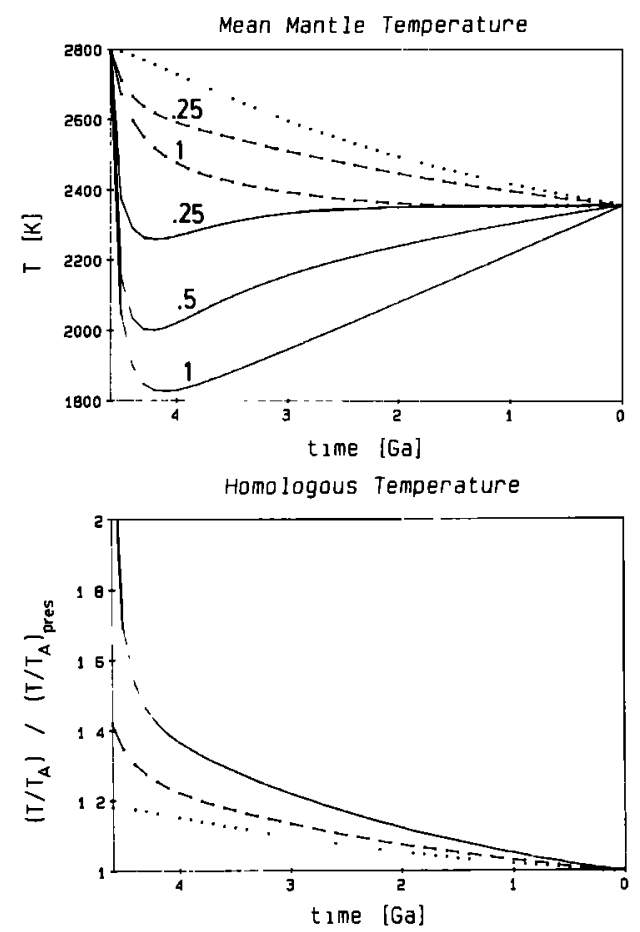

Figure 1. Results of parameterized mantle convection model with a time-dependent activation temperature. Top: Evolution of characteristic mantle temperature. Dotted line is for volatile-independent model; dashed lines for $20 \%$ increase in $T_{A}$; solid lines for factor of two increase; $\tau$ values indicated for each curve. Bottom: Corresponding homologous temperature $T / T_{A}$ for $\tau=1$, normalized to present-day value.

accommodated with $\tau$ values near 1 , for which $T_{A}(t)$ increases linearly throughout earth history.

We consider first two end-member models, one with no change in activation temperature (i.e. a volatileindependent rheology), and one in which the activation temperature is strongly volatile-dependent, increasing by a factor of two over earth history. The latter model, which also implies a factor of two increase in the mantle solidus temperature, is not proposed as realistic, but is intended to illustrate limiting end-member behavior. A third intermediate model derived from the data in Table 1 and an initial/present $\mathrm{H}_{2} \mathrm{O}$ content ratio of 3 yields a $20 \%$ increase in activation temperature, representing a more moderate departure from the traditional volatileindependent model. For each of the volatile-dependent models, both early rapid $(\tau=0.25)$ and continuous linear $(\tau=1.0)$ devolatilization histories are considered.

\section{Results}

Figure 1 shows the characteristic mantle temperature through geologic time for each of the models. The volatile-independent model yields monotonically decreasing temperature and increasing viscosity. Temperature variations in the strongly volatile-dependent models are far more drastic, and clearly not monotonic. In the early stage, high temperatures coupled with the low activation energy for solid-state creep lead to very low viscosities, rapid convection and rapid heat loss. The mean mantle temperature reaches a minimum when the ac- tivation temperature and viscosity increase enough to retard convection significantly, and radiogenic heat begins to accumulate. From the minimum onward in time the planet warms. For early rapid degassing models, this minimum is reached slightly earlier, and at considerably higher temperatures. Results for the $20 \%$ model are intermediate between the end-member models. The temperature decreases monotonically for $\tau<1$, but with very slow cooling rates, on the order of $30^{\circ} \mathrm{Ga}^{-1}$ from the late Archean onward. For the model with $\tau=1$, the mantle is nearly isothermal over much of its history; the temperature reaches a barely perceptible minimum at about $1 \mathrm{Ga}$ ago, and increases only slightly thereafter.

Also shown in Figure 1 is the evolution of the homologous temperature $T / T_{A}$. Following the initial phase of rapid adjustment, the homologous temperatures slowly decrease at a rate determined by the devolatilization time constant. It is evident that despite the strong differences in actual temperature histories for the volatiledependent and volatile-independent models, the homologous temperature behaves essentially the same way in both models.

Figure 2 shows how the Urey ratio (heat production/heat loss) depends upon the fractional change in $T_{A}$ over the age of the earth. For large and probably unrealistic increases in $T_{A}$ ( $50 \%$ or greater), only small values of $\tau$, corresponding to rapid early volatile loss, result in present-day Urey ratios less than $100 \%$, and therefore a cooling earth. For more plausible increases in $T_{A}$, less than about $25 \%$, Urey ratios exceeding $100 \%$ still arise for $\tau$ values of 0.75 or more, i.e., for relatively continuous degassing models. Because we impose the present-day heat loss as a boundary condition on all the models, the Urey ratio is also linearly related to heat production. Figure 2 shows the initial heat production required by the various models. A present-day Urey ratio of 1.0 requires about $25 \%$ higher heat production than is needed for a ratio of 0.8 typical of volatileindependent models. Direct geochemical estimates of mantle heat production lack the resolution to discriminate between these cases.

\section{Discussion and Conclusions}

Tozer [1972] argued that a strongly temperaturedependent viscosity (with constant $T_{A}$ ) would regulate

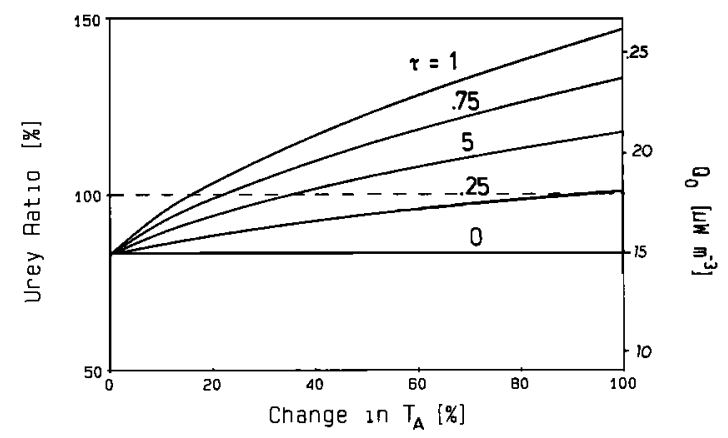

Figure 2. Present-day Urey ratio and required initial heat production as a function of the fractional change in activation temperature over earth history. Large changes in $T_{A}$, or moderate changes in $T_{A}$ with values of $\tau$ corresponding to slow, continuous degassing give rise to Urey ratios $>1$. 
planetary interiors to nearly constant temperatures. Our results show that this concept can be stated more generally in terms of a nearly constant homologous temperature in a system with rheology dependent also upon volatiles. Due to the secular decrease in radiogenic heating, homologous temperature must decrease slowly with time. However, we have shown that a similar decline does not necessarily occur for actual temperature.

A number of studies [e.g. Schubert et al., 1980; Davies, 1980] have used parameterized models to attempt to place bounds on the mantle cooling rate and Urey ratio. Principal conclusions of these studies were that the mantle is presently cooling at about $100^{\circ} \mathrm{Ga}^{-1}$ and that the Urey ratio can be as low as 0.5 or less [Sharpe and Peltier, 1978; Davies, 1980] and no higher than about 0.8 [Schubert et al., 1980]. We have previously pointed out [Jackson and Pollack, 1984] that these upper bounds are sensitive to the $\mathrm{K} / \mathrm{U}$ ratio in the mantle, and concluded that Urey ratios as high as 0.9 cannot be ruled out. The results we present here suggest that plausible models of devolatilization and rheology require another upward revision of the upper bound on the Urey ratio, even to admitting the possibility that current heat production exceeds the present-day heat loss and therefore the Earth is warming.

\section{References}

Carter, N. L., Steady-state flow of rocks, Rev. Geophys. Space Phys., 14, 301-360, 1976.

Chopra, P. N., and M. S. Paterson, The role of water in the deformation of dunite, J. Geophys. Res., 89, 7861-7876, 1984.

Davies, G. F., Thermal histories of convective earth models and constraints on radiogenic heat production in the earth, J. Geophys. Res., 85, 2517-2530, 1980.

Eggler, D. H., The effect of $\mathrm{CO}_{2}$ upon partial melting of peridotite in the system $\mathrm{Na}_{2} \mathrm{O}-\mathrm{CaO}-\mathrm{Al}_{2} \mathrm{O}_{3}-\mathrm{MgO}$ $\mathrm{SiO}_{2}-\mathrm{CO}_{2}$ to $35 \mathrm{~kb}$, with an analysis of melting in a peridotite- $\mathrm{H}_{2} \mathrm{O}-\mathrm{CO}_{2}$ system, Am. J. Sci., 278, 305$343,1978$.

Fisher, D., Radiogenic rare gases and the evolutionary history of the depleted mantle, J. Geophys. Res., 90, 1801-1807, 1985.

Fisher, D., Reply to Staudacher and Sarda, J. Geophys. Res., 92, 2813-2817, 1987.

Green, D. H., Experimantal melting studies on a model upper mantle composition at high pressure under water-saturated and water-undersaturated conditions, Earth Planet. Sci. Lett., 19, 37-53, 1973.

Jackson, M. J., and H. N. Pollack, On the sensitivity of parameterized convection to the rate of decay of internal heat sources, J. Geophys. Res., 89, 1010310108, 1984.

Jaoul, O., J. Tullis, and A. Kroneneberg, The effects of varying water contents on the creep behavior of Heavitree Quartzite, J. Geophys. Res., 89, 4298-4312, 1984.
Justice, M. G. Jr., E. K. Graham, R. E. Tressler, and I. S. T. Tsong, The effect of water on high temperature deformation in olivine, Geophys. Res. Lett., 9, 10051008, 1982.

Kronenberg, A. K., and J. Tullis, Flow strengths of quartz aggregates: Grain size and pressure effects due to hydrolytic weakening, J. Geophys. Res., 89, 42814297, 1984.

Larimer, S., Composition of the earth: Chondritic or achondritic?, Geochim. Cosmochim. Acta, 35, 769786, 1971.

Mysen, B. O. and A. L. Boettcher, Melting of a hydrous mantle, J. Petrol., 16, 520-548, 1975.

Paterson, M. S., Problems in the extrapolation of laboratory rheological data, Tectonophysics, 139, 33-43, 1987.

Post, R. L., High temperature creep of the Mt. Burnet dunite, Tectonophysics, 42, 75- 110, 1977.

Richter, F. M., H.-C. Nataf, and S. F. Daly, Heat transfer and horizontally averaged temperature of convection with large viscosity variations, J. Fluid Mech., 129, 173-192, 1983.

Ringwood, A. E., The chemical composition and origin of the Earth, in Advances in Earth Science, P. M. Hurley, ed., M.I.T. Press, Cambridge, p. 287-356, 1966.

Ringwood, A. E., Composition and Petrology of the Earth's Mantle, McGraw-Hill, New York, 1975.

Sarda, P., T. Staudacher, and C. J. Allegre, 40Ar/36Ar in MORB glasses: constraints on atmosphere and mantle evolution, Earth Planet. Sci. Lett., 72, 357375,1985

Schubert, G., and C. A. Anderson, Finite element calculations of very high Rayleigh number thermal convection, Geophys. J. R. astr. Soc., 80, 575-602, 1985.

Schubert, G., D. Stevenson, and P. Cassen, Whole planet cooling and the radiogenic heat source contents of the earth and moon, J. Geophys. Res., 85, 2531-2538, 1980.

Staudacher, T. and P. Sarda, Comment on "Radiogenic rare gases and the evolutionary history of the depleted mantle", by D. E. Fisher, J. Geophys. Res., 92, 28082812, 1987.

Tozer, D. C., The present thermal state of the terrestrial planets, Phys. Earth Planet. Int., 6, 182-197, 1972.

Weertman, J., and J. R. Weertman, High temperature creep of rock and mantle viscosity, Ann. Rev. Earth Planet. Sci., 3, 293-315, 1975.

Wyllie, P. J., Magmas and volatile components, $A m$. Mineral., 64, 469-500, 1979.

Michael J. Jackson and Henry N. Pollack, Department of Geological Sciences, The University of Michigan, Ann Arbor, MI 48109-1063.

(Received: April 10, 1987

revised : May 27, 1987

accepted: May 27, 1987.) 